\title{
Student Learning Objectives (SLOs): Collaboration for Student Success
}

\author{
Jennifer Locraft Cuddapah (Corresponding author) \\ Education Department, Hood College \\ 401 Rosemont Ave., Frederick, MD 21701, United States \\ Tel: 1-301-696-3773Ｅ-mail: cuddapah@hood.edu
}

\author{
Shabana Sayed \\ Science Department, Marylandville Middle School \\ 6251 Darlington Ct., Frederick, MD 21703, United States \\ Tel: 1-240-446-3941Ｅ-mail: ssayed57@gmail.com
}

Received: September 10, 2019 Accepted: October 20, 2019 Published: November 15, 2019

doi:10.5296/gjes.v5i2.15423 URL: https://doi.org/10.5296/gjes.v5i2.15423

\begin{abstract}
A middle school science teacher and a college teacher educator collaborate to explain how the Student Learning Objective (SLO) was embedded into the student teaching internship. After review of the SLO literature, details about the process and benefits of partnering with a mentor teacher in order to learn about the SLO implementation cycle are shared. Implications for future practice are offered.
\end{abstract}

Keywords: Student Learning Objective (SLO), Collaboration, Preservice teachers, Teacher education 


\section{Introduction}

Having a positive impact on student learning is at the core of what good teachers are expected to do. At the same time states, districts, and schools receiving federal funding grapple with the best ways to document and track teacher impact on students, teacher preparation programs seeking accreditation are expected to indicate how they prepare candidates to impact students. Since teacher education candidates fulfill the on-the-job learning portion of their program in schools with mentor teachers, the mutual goal of impacting student achievement is situated at the intersection of the intern, school, and university.

At the university level, a common means for documenting impact is through action research methods targeted at making changes in teaching practices to improve student achievement (Dana, 2013; Hine \& Lavery, 2014; Mills, 2014). At the school level, an increasingly popular avenue for measuring student growth is through Student Learning Objectives (SLOs). Many states and districts are now mandating that teachers write and implement SLOs to indicate effectiveness in working with students (Buckley, 2015; Lacireno-Paquet, Morgan, \& Mello, 2014). In Maryland, where both authors taught at the time of this research, the SLO process was adopted, and many districts mandated that all teachers write SLOs each year. To help prepare teacher education candidates for this mandate, the traditional form of action research needed to be changed at the college level.

In this paper, two authors collaborate to describe the process used to facilitate learning about and implementing the SLO. One author, Jennifer, is the teacher educator who designed a scaffolded SLO project for teacher candidates to use in partnership with mentors during the student teaching internship. During her student teaching internship year, while earning teacher certification from Hood College where Jennifer teaches, the other author, Shabana, used the scaffolded SLO project as she worked alongside her mentor teacher. In her first year of professional teaching, Shabana independently implemented a similar SLO for a second cycle. After a brief description of SLOs, an explanation of Hood College's scaffolded process for SLOs for teacher preparation candidates follows. Presented next is Shabana's SLO, implemented for two consecutive cycle years, first as a student teacher under the guidance of her mentor and next as a first-year middle school science teacher. Following a discussion of the benefits and challenges of learning about the SLO through a teacher preparation program, implications for future practice are offered.

\section{Student Learning Objectives (SLOs)}

The Center on Great Teachers and Leaders (2013) define an SLO as "a measurable, long-term, academic goal informed by available data that a teacher or team of teachers establish at the beginning of the year for all students or for subgroups of students" (p. 6). While it is most common for individual teachers to compose their own SLOs, they can be written by teams or even whole schools (Lacireno-Paquet, Morgan, \& Mello, 2014). Nevertheless, a well-written SLO is precise and measurable so that attainment can be easily discerned. Its formality is akin to an Individualized Education Plan (IEP), but while individual student data are tracked, the focus of an SLO is on an identified group or groups of students rather than the individual. To create an SLO, teachers write goals linked to their course content standards. Next, they 
determine or generate assessments to measure performance in relationship to these goals. Additionally, teachers specify targets for individual or groups of students which will reflect whether or not goal was achieved (Buckley, 2015).

While Student Learning Objectives or SLOs began in Denver in 1999 (Reform Support Network, 2012), they gained tremendous momentum and continue to be a burgeoning practice (Lacireno-Paquet, Morgan, \& Mello, 2014). The Center on Great Teachers and Leaders (2013) indicates that SLOs were tied to Teacher Incentive Fund (TIF) compensation in Denver, Austin, and Charlotte-Mecklenburg - the early adopting districts. More recently, SLOs are used as documentation for teacher evaluation requirements stemming from funding received through Race to the Top, ESEA waivers, and TIF (Buckley, 2015; Lacireno-Paquet, Morgan, \& Mello, 2014). Lachlan-Haché (2015) indicates that over half the states currently use SLOs in conjunction with their teacher evaluation systems. Yet, there is a great deal of variation in how SLOs are implemented and tracked from one district and state to another (Lachlan-Haché, Matlach, Reese, Cushing, \& Mean, 2013).

Because widespread adoption of SLOs is so recent, there is a dearth of empirical research (Lacireno-Paquet, Morgan, \& Mello, 2014). Aside from quantitative evaluations from Denver (see Slotnick, Smith, Helms, \& Quao, 2004), Austin (see Schmitt, Lamb, Cornetto, \& Courtemanche, 2013), and Charlotte-Mecklenburg (see Slotnick, Smith, Helms, \& Quao, 2013), what does exist in the literature are mostly practitioner-oriented documents created by and for particular states and school districts about requirements and processes for SLO writing. One example is the Reform Support Network (2012) manual which is described as a toolkit for Race to the Top grantees as they roll out an SLO process. There are some manuscripts about SLOs from nonpartisan, nonprofit research agencies. For example, in one publication, Lachlan-Haché, Cushing, and Bivona (2012a) describe how to implement SLOs. Because of the limited quantitative evidence about SLOs, Buckley (2015) embarked on a study to investigate the validity and reliability of teacher SLO scores in one state. As a result of the findings from her dissertation research, Buckley calls for more perfected assessments as well as consistency in growth targets to improve validity of SLO scores.

Lachlan-Haché, Cushing, and Bivona (2012b) outline some challenges of SLOs and what can be done to mitigate these. The authors describe the need to be cognizant around issues of identifying specific baseline data and appropriate assessments as well as indicating appropriate student targets and achievable goals. In a similar vein of caution and advice, Marion, DePascale, Domaleski, Gong, and Diaz-Billelo (2012) highlight the need to remain vigilant around assessment particularly because the teacher, who stands to gain or lose as the result of the high-stakes measures, is the very person responsible for developing and giving them. Slotnik, Bugler, and Liang (2014) also summarize challenges which they found through their interview, focus group, and survey research of evaluating the implementation of state-wide SLOs tied to teacher evaluation in Maryland. Although they found that educators responded positively to SLOs and felt more confident implementing them from one year to the next, they also learned that teachers have concerns about lacking preparation and training to understand and create high quality SLOs as well as questions about whether their principals are ready to adequately assist them. Lachlan-Haché (2015) synthesizes the existing research on SLOs and 
offers implications for policy and practice moving forward. Findings from the studies reviewed in the synthesis "highlight some potential benefits of SLOs, including potential effects on teacher practice" (p. 9). These potential benefits can be used as motivation to address the challenges seen in early implementation. Our own experiences with supporting teacher preparation candidates learning about and implementing SLOs, while being supported by the mentor teacher, during the student teaching internship add to this growing research base.

\section{Research Context}

Hood College is a private, liberal arts college in the Mid-Atlantic with about 2400 students at the undergraduate and graduate levels. The Education Department serves around a fifth of the students attending the college. The undergraduate education programs prepare candidates for certification eligibility in Maryland. The graduate programs in curriculum and instruction, reading, and educational leadership are aimed at in-service teachers. Most of the students enrolled in the college live in the general vicinity of the college, although there are some boarding undergraduates housed on campus.

Any time a Hood College student is enrolled in an education course, s/he is also placed in a Professional Development School (PDS) placement for that same semester. There is a purposeful and strong connection between the theory and practices learned at the college level and the implementation in public schools. The college-to-classroom linkage is evidence of the Education Department's mindful focus on inquiry aimed at analyzing practice and student data in order to improve teacher and student learning.

Secondary education candidates seeking initial certification complete a major in the content area they wish to teach as well as 37 credits of pedagogy coursework. Some students seeking licensure, who have already earned bachelor's degrees in the content area, come through the education portion of the program as a post-baccalaureate candidate. In the final year of education classes, secondary candidates complete a year-long internship spread across two semesters in one of the college's PDSs. In the first semester of the internship, candidates work with a mentor for one and a half days per week. Because the candidate is simultaneously taking courses in teaching methodology, special needs students, classroom management, and finishing the content major, s/he gradually assumes teaching responsibility in the first semester. In the second semester, candidates are assigned to their PDS and mentor's classroom full-time. During the full-time student teaching phase, candidates are expected to fulfill complete teaching responsibilities and take over the full load of the mentor according to a specified time table informed by conferences with the candidate, mentor, and university supervisor. Jennifer is a full-time faculty member at Hood College and is the Secondary Program Coordinator. Shabana completed the post-baccalaureate track of the program leading to Secondary Biology certification. After finishing the program, she was hired to teach seventh grade at Marylandville* Middle School (pseudonym).

Located in a semi-rural area about 45 minutes in between and away from Washington DC and Baltimore cities, Shabana's middle school is home to approximately 800 students across grades 6,7 , and 8 . The demographic breakdown of the school is as follows with percentages being rounded: $75 \%$ White, 12\% African American, 7\% Latino, 3\% Asian American, 3\% two or 
more races, and 1\% American Indian, Alaskan Native, Hawaiian, or Pacific Islander. About $25 \%$ of students qualify as FARMS; about $10 \%$ of students are identified as Special Education; and about 5\% of students are Limited English Proficiency (LEP). The structure of the school day is a typical 7-period rotation with about 30 students in each class.

\section{Learning about SLOs Hood College}

Influenced by both Specialty Program Area (SPA) content requirements for accreditation as well as by sound educational practice for novice teachers, the secondary program at Hood College has required candidates to complete an action research project during the full-time student teaching semester. This project was embedded in the final exit folio, which is a standards-based, analytical compilation of the work candidates have completed in their courses and PDS placements while in their program. Jennifer felt that the action research project was somewhat buried in the exit folio as one of 10 artifacts and sought to showcase its importance by pulling it out of the exit folio requirements and working on it as part of coursework.

Maryland's adoption of SLOs coincided with the year Jennifer was looking to make changes to the way the action research project was supported and reported. Because the partnering school district where Marylandville Middle is located was requiring teachers to write SLOs, Jennifer thought it made sense to consider the impact of this on the student teachers being placed in these PDSs. The thinking was that teacher preparation candidates would see what it was like to receive a state and district mandate and go through the rollout over the course of the year. Knowing that there were many unknowns about what SLOs would look like in this district made it a ripe learning experience for the novices at Hood College. After all, as professional teachers, they would certainly be on the receiving end of federal, state, and local mandates; it seemed to make sense to scaffold the experience and discuss it during class time while they were in the learning phase of their preparation. Collaboration between a college, school, mentor, and student teacher is form of on-the-job learning bridging theory and learning to practice. This is akin to a clinical rounds framework for learning adapted from the field of medicine into the student teaching experience. When mentors model and articulate the rationale behind their decisions, they prepare their student teacher interns to understand the thinking behind the problem-solving (Cohen, Field, Cuddapah, \& Masci, 2012).

The Secondary PDS Liaison at Hood College attended some district meetings and came back with handouts and ideas about the importance of SLOs for the district in the upcoming year. The district made the first two years of SLOs "no fault" in that teacher evaluations would not be negatively impacted by results while educators were still learning the process. As the Secondary PDS Liaison and Jennifer looked over the paperwork and discussed the nature of SLOs, they saw many similarities with the action research steps required in the projects secondary candidates completed. Jennifer suggested rewriting the action research project as an SLO project that candidates would work on alongside their mentor teachers. In the first semester of student teaching, when they were in their school placements for just one and a half days per week, the interns would attend the SLO meetings with their mentors, discuss the SLO ideas, and come up with a plan of action for how each would be involved. In theory, having an intern would be of benefit to the mentor because there would be an extra set of instructional 
hands involved in working with the targeted students.

Using the guiding questions disseminated by the state and district and meshing it with the existing action research components, Jennifer created an SLO template (see Appendix 1 for prompts). The context, planning, and baseline data analysis portions could easily be completed during the first semester of student teaching (see gray highlight portions of Appendix 1). These sections were covered during the first semester student teaching seminar course. The rest of the template could be completed in the second semester when the candidate was at the PDS full time. The completed template was turned in during the full time internship seminar course. The SLO would be the mentor's. The role the intern would serve in implementing the SLO would be mutually determined by the mentor and intern. Interns would learn what SLOs were by observing and writing them with their mentors. On a practical level, they would then be knowledgeable about required components and jargon of SLOs. On a deeper level, they would begin to see the complexity of determining attainable goals, describing targets for actual students, and creating/implementing quality assessments. These steps were similar in many ways to the action research process that the connections between SLOs and action research had to be made as part of the teacher preparation process.

Jennifer gave the SLO template created to the PDS Coordinator and Liaison for feedback. It was also vetted by some secondary mentors and university supervisors. The first semester the finalized template was used by the three students enrolled in the full-time student teaching seminar. The next semester, which is when Shabana was enrolled in the student teaching seminar course, there were eight students who completed the SLO in collaboration with their mentor teachers. In the next section, Shabana describes her experiences with the SLO during her student teaching year as well as during her first year of teaching at Marylandville Middle.

\section{Shabana's SLO Experiences}

In this section, Shabana writes about her experiences learning about and implementing 2 cycles of the SLO. The first year, she was a student teacher working alongside her mentor in implementation of the mentor's SLO. The second year, she was hired to teach science at the same school and had the opportunity to independently implement her own SLO. These two cycles of experience revealed some of the benefits and challenges implementing the SLO.

\subsection{Cycle 1: Collaboration with Mentor Teacher on SLO}

As a student teacher at Marylandville Middle School, I attended science department meetings and collaborated often with my mentor teacher. My mentor teacher and I wrote an SLO aligned with the school improvement plan that supported argumentative writing in classrooms as well as disciplinary literacy. This goal could be reached by students in the science classroom. In order to successfully make an argument, students must understand the cause and effect relationships that happens in science. They would demonstrate that understanding by writing logical arguments in their lab conclusions.

To determine whether students were making improvements in argumentative writing and disciplinary literacy, they were assessed on three specific measures. We looked at rubric scores for the science fair project, a summative assessment of science skills and processes, and 
conclusions from lab reports. Because these measures required students to engage in focused research, analyze data, and write conclusions with supporting evidence, the school-wide goal on disciplinary literacy was supported. Once we had decided what measures would be used to determine success with our SLO, my mentor teacher and I began to think about baseline data collection. It was important for us to establish a baseline of where our students were to determine what improvements we would expect to see from them by the end of the instructional interval as well as to guide our instructional processes. Therefore, we gave a skills and processes pre-assessment. These scores as well as an independent science investigation using the scientific method, with minimal instruction, formed our baseline.

Baseline data were analyzed by determining skill gaps in students' application of the scientific process. My mentor teacher reviewed the data, focusing on student population results and looking for patterns in student demographics while I compiled commonly missed questions and determined student weaknesses with using the scientific method to solve problems. Students who scored below average on the specified baseline data points, most notably on the scientific skills and processes assessment and an independent investigation using the scientific method, were targeted. There were two students from each class period for a total of 10 students, an equal number of boys and girls. Our goal was for $85 \%$ of the targeted students to score $80 \%$ or higher on summative assessments, which included the final Science Fair Projects, a final lab conclusion, and an assessment of scientific skills and processes.

\subsubsection{Cycle 1: Implementation}

My role in implementing the SLO was to work alongside my mentor to implement a variety of instructional strategies, such as repetition, guided questions, problem-solving, independent investigations, lab activities, and using graphic organizers, to teach not just our target students, but all of our students. We worked together to create lessons and used formative assessments to monitor student progress. My mentor encouraged me to enhance and improve her past lessons. I took those lessons and analyzed how they could be used with the current student population to make the biggest impact on learning. For example, my mentor originally taught the steps of the scientific method using guided notes and a worksheet with examples. When we looked at this lesson together, we began to brainstorm ways in which this lesson could be enhanced. We wanted to reach multiple learners while still staying true to the content that needed to be taught. We knew we had visual, auditory, and tactile learners. I suggested teaching the steps of the scientific method using stations, turning each individual step into its own station of learning. Some stations would require reading and writing while other stations involved manipulating items, drawing models, and working with numbers. My mentor was excited to try something different and was even willing to co-teach this lesson with me. We incorporated technology into some of the stations as well to provide a multi-faceted learning experience for our students. The results were great. The students enjoyed the change of pace that stations allowed for and were able to recall the content based on their experiences at each station. Instead of copying notes, the students were able to work directly at "doing" each step of the scientific method using different activities, which created a better learning experience.

As part of regular science instruction, students worked on their independent science fair 
projects which included checkpoints along the way to monitor progress with using the scientific method. Students received detailed comments to guide work for their final projects. Also, independent investigation lab activities were used as formative assessments of application of science skills and processes. Post assessments were administered to track the effectiveness of each.

My mentor and I worked closely with an administrator throughout the instructional interval of the SLO during my internship at Marylandville Middle School. She reviewed our first SLO draft at the beginning of the school year to help guide us towards a manageable, effective SLO. She also helped us align our SLO with the School Improvement Plan. Once we finalized our SLO, our administrator provided us with resources to help us with planning and formative assessments. We met with her a few times throughout the year to monitor our SLO progress and to document our instructional strategies. She provided invaluable insight on growth measures and data collection.

\subsubsection{Cycle 1: Results}

The results of my first experience working alongside my mentor on her SLO were exciting. Overall, the goals of the SLO were met successfully. Specifically, data indicated that $90 \%$ of the targeted students scored above average, with only one student scoring below the $80 \%$ benchmark. More than $85 \%$ of the target students earned an $80 \%$ or higher on summative assessments over the course of the year with $90 \%$ of them scoring above $80 \%$ on the scientific skills and processes assessment and $100 \%$ of them scoring above $80 \%$ on the final science fair projects.

\subsection{Cycle 2: Independent Implementation of SLO}

After completing my secondary education certification program, I was hired as a science teacher at Marylandville Middle School. Because of my experiences there as an intern, I felt prepared to write and implement my own SLO. I drew from my mentor teacher's SLO as my starting point.

The biggest difference between writing an SLO with my mentor teacher and writing it on my own involved the science department at Marylandville Middle School. During my first year of teaching, the science department had met early in the school year and decided, unanimously, to align our SLOs across the department. We discussed what did and did not work with previous SLOs. We decided to use our SLOs to impact student progress, not only over the yearly instructional interval, but also over the three years that students spend were at the middle school.

Since scientific skills and processes are practiced every year in middle school science, this topic made sense for the whole department. This meant that my own SLO would not change drastically from the prior year. I shifted the focus from conclusion writing skills to data analysis skills. Students should be able to take the data that they collect in an experiment or activity and make sense of it. They should be able to determine the relationships that exist between the variables of their experiment and demonstrate an understanding of how those variables change as a result of the experiment itself. Conclusion writing skills were still taught but were not the 
main focus of my SLO. The shifted focus also meant I needed to change the instructional strategies used throughout the SLO interval. I reflected on strategies and lessons that worked well for the students the previous year and adapted these to fit my new goals and target students.

As a department, we decided to continue using science fair project checkpoints as a formative assessment measure of progress. Because all students are required to complete a science fair project during their time in middle school, we would be able to collect and compare data on students every year. Checkpoints were instrumental in demonstrating the strengths and weaknesses of students in regards to the scientific method and scientific process of inquiry. Another significant change with my SLO for this cycle involved the summative assessments. Because science fair projects were completed outside the classroom, we discussed as a department that they could not be used as a summative assessment as was the case the previous year. Instead, it could be a formative assessment.

With these changes, I reflected upon what worked for me as a teacher the past year and what worked for my students. I then reevaluated how those things could be used and implemented the next year with a new student target group. I felt very prepared to embrace these changes and grow alongside my students through this process. I never once felt unsure of how to teach the skills and processes nor how to measure that growth. My experiences as an intern had proved, once again, invaluable in this situation.

\subsubsection{Cycle 2: Results}

The results of my first independent SLO were that the students improved in data analysis and conclusion writing. At the beginning of the instructional interval, all students were pre-assessed on the steps of the scientific method as well as data analysis skills. Students were also given a lab to complete, which included data analysis and conclusion writing to provide a basis for which progress could be determined. Throughout the instructional interval, multiple formative assessment techniques were utilized to allow students to improve data analysis and conclusion writing skills. These formatives included labs, county generated content assessments, graphing activities, and science fair projects. At the end of the instructional interval, all twelve of my targeted students improved in their analysis of data and conclusion writing. These improvements were demonstrated in their post-assessments and their final independent lab activity.

\section{Benefits and Challenges of SLOs and the Implications for Practice}

Embedding the Student Learning Objective (SLO) into the student teaching internship proved a fruitful professional learning and research experience. Shabana reaped the benefits of having a mentor teacher to work closely with on setting an SLO, determining reasonable growth target expectations, and planning meaningful instruction for their science students. Shabana was able to see the immediate benefits of reflecting on the impact of instructional approaches on her students' learning and making important changes as a result. She was able to further benefit from this partnership in her second year when she completed her SLO independently. Shabana had a practical SLO experience upon which to draw and improve. She was better equipped to 
adapt successfully to the changes the department members decided to implement. The implication for practice is for teacher preparation programs to collaborate with partnering school districts to facilitate new entrants to the field in their learning about identifying valid baseline data and fitting formative and summative assessments, supporting what has been called for by Lachlan-Haché, Cushing, and Bivona (2012b) as well as Marion et al. (2012).

Not only did Shabana benefit from her mentor's collaboration, but she also drew upon the support and guidance of her teacher preparation program cohort members. Because the SLO process was linked to her seminar coursework, there were other students fulfilling a similar course of action in their respective content areas and schools. The details of each SLO were unique to the students, but the expectations from the partnering county and the college were the same. Shabana gained from her weekly discussions with her peers on difficulties, successes, ideas, and questions related to SLOs across a variety of content areas. In a particular instance, she drew from an English intern who helped her with instructional suggestions aimed at teaching writing which helped with the science fair projects. While academic research experiences tend to be completed independently, both the literature and practical experiences point to the collaborative nature of school-based research (e.g., Lacireno-Paquet, Morgan, \& Mello, 2014). Another implication for teacher education practice is to acknowledge this reality and plan for processes which facilitate partnerships in SLO and research methods.

In terms of challenges, one thing that did not happen but would have perhaps been a good component to include in the learning process were opportunities for mentor teachers and interns from the entire cohort to meet and discuss successes and difficulties with SLO writing and implementation. This extra level of collaboration could benefit both mentors and interns who may have been struggling with understanding and incorporating the elements of the SLO. Another challenge, from Jennifer's perspective, was the high-stakes nature and embedded assumptions behind the entire SLO mandate. While the interns might not have had enough teaching experience to question SLOs and their purposes, there may have been some who heard mentors' critiques about SLOs. Teacher preparation programs are appropriate venues for teaching about and processing these varying perspectives. Understanding the history of SLOs, the purposes they serve in different districts, and the potential benefits and consequences are the teaching responsibility of preparation programs.

Both Jennifer and Shabana believe that experiencing an actual SLO as part of the student teaching internship is a valuable authentic practice for collaborative educational research. Not only are there opportunities for professional collaboration and growth, but there are also chances for interns to better understand what a high-stakes mandate looks like in practice. Shabana's experiences with the SLO in her internship year and her first year of teaching were enhanced because she learned and talked about the SLO with her cohort members, her course instructor, and her mentor teacher the first year and then drew upon this experience in order to collaborate with her department members the following year.

\section{References}

Buckley, K. H. (2015). Separating the signal from the noise: An Examination of student and teacher scores based on Student Learning Objectives (SLOs) in one state. Doctoral dissertation, 
Harvard

Graduate

School

of

Education.

http://nrs.harvard.edu/urn-3:HUL.InstRepos:16461041

Center on Great Teachers and Leaders. (2013). Professional learning module: Introduction to student learning objectives: Facilitator's guide. Washington, DC: American Institutes for Research. Retrieved from http://www.gtlcenter.org/sites/default/files/IntroSLOs_FacilitatorGuide_2.pdf

Cohen, L., Field, T., Cuddapah, J. L., \& Masci, F. J. (2012). Operating Theater: Preparing teachers through a school-university collaboration. Excelsior: Leadership in Teaching and Learning, 7(1), 71-81.

Dana, N. F. (2013). Digging deeper into action research: A Teacher inquirer's field guide. Thousand Oaks, CA: Corwin.

Hine, G. S. C., \& Lavery, S. D. (2014). Action research: Informing professional practice within schools. Issues in Educational Research, 24(2), 162-173. Retrieved from http://researchonline.nd.edu.au/cgi/viewcontent.cgi?article=1150\&context=edu_article

Lachlan-Haché, L. (2015). The Art and science of Student Learning Objectives: A Research Synthesis. Washington, DC: American Institutes for Research. Retrieved from http://www.air.org/sites/default/files/downloads/report/Art-and-Science-of-Student-LearningObjectives-April-2015.pdf

Lachlan-Haché, L., Cushing, E., \& Bivona, L. (2012a). Implementing student learning objectives: Core elements for sustainability. Washington, DC: American Institutes for Research. Retrieved from https://www.air.org/sites/default/files/downloads/report/Student-Learning-Objectives-Implem entation.pdf

Lachlan-Haché, L., Cushing, E., \& Bivona, L. (2012b). Student learning objectives: Benefits, challenges, and solutions. Washington, DC: American Institutes for Research. Retrieved from https://www.air.org/sites/default/files/downloads/report/Student-Learning-Objectives-Benefit s-Challenges-Solutions.pdf

Lachlan-Haché, L., Matlach, L., Reese, K., Cushing, E., \& Mean, M. (2013). Student learning objectives: Early lessons learned from the Teacher Incentive Fund. Washington, DC: American Institutes for Research.

Lacireno-Paquet, N., Morgan, C., \& Mello, D. (2014). How states use student learning objectives in teacher evaluation systems: A review of state websites (REL 2014-013). Washington, DC: U.S. Department of Education, Institute of Education Sciences, National Center for Education Evaluation and Regional Assistance, Regional Educational Laboratory Northeast and Islands. Retrieved from http://ies.ed.gov/ncee/edlabs/regions/northeast/pdf/REL_2014013.pdf

Marion, S., DePascale, C., Domaleski, C., Gong, B., \& Diaz-Billelo, E. (2012).Considerations for analyzing educators' contributions to student learning in non-tested subjects and grades with a focus on student learning objectives. Concord, NH: Center for Assessment. Retrieved from

https://www.nciea.org/library/considerations-analyzing-educators-contributions-student-learn ing-non-tested-subjects-and 
Mills, G. E. (2014). Action research: A guide for the teacher researcher (5th ed.). Boston, MA: Pearson.

Reform Support Network. (2012). A quality control toolkit for student learning objectives. Washington, DC: Author. Retrieved from https://www2.ed.gov/about/inits/ed/implementation-support-unit/tech-assist/slo-toolkit.pdf

Schmitt, L. N. T., Lamb, L. M., Cornetto, K. M., \& Courtemanche, M. (2013). AISD REACH program update, 2012-2013: Student Learning Objectives (DRE Publication No. 12.83a). Austin, TX: Austin Independent School District. Retrieved from https://www.austinisd.org/sites/default/files/dre-reports/DRE_12.83_AISD_REACH_Progra m_Update_2012_2013_Student_Learning_Objectives.pdf

Slotnick, W. J., Smith, M. D., Helms, B. J., \& Quao, Z. (2004). Catalyst for change: Pay for performance in Denver final report. Boston, MA: Community Training and Assistance Center. Retrieved from http://www.ctacusa.com/wp-content/uploads/2013/11/CatalystForChange.pdf

Slotnick, W. J., Smith, M. D., Helms, B. J., \& Quao, Z. (2013). It's more than money: Teacher Incentive Fund - leadership for educators' advanced performance Charlotte-Mecklenburg Schools. Boston, MA: Community Training and Assistance Center. Retrieved from http://ctacusa.com/wp-content/uploads/2013/11/MoreThanMoney.pdf

Slotnik, W. J., Bugler, D., \& Liang, G. (2014). Real progress in Maryland: Student Learning Objectives and teacher and principal evaluation. (A report from the Mid-Atlantic Comprehensive Center at WestEd.) San Francisco, CA: WestEd and Boston, MA: Community Training and Assistance Center. Retrieved from https://www.wested.org/resources/real-progress-in-maryland-59136/

\section{Appendix}

Appendix 1. Hood College Secondary Program SLO Template

\begin{tabular}{|c|}
\hline Action Research Process through SLO Guiding Questions Responses \\
\hline $\begin{array}{l}\text { SCHOOL PRIORITY ALIGNMENT: Discuss student needs with your mentor and PDS site } \\
\text { coordinator. Review school goals, paying attention to those that directly relate to your subject area } \\
\text { or classes. Review any rationale for the plans, the reasons the population/students have been } \\
\text { targeted, where/when any existing interventions take place. }\end{array}$ \\
\hline $\begin{array}{l}\text { DATA REVIEW \& BASELINE EVIDENCE: Find out what data are available which support the } \\
\text { school goals. Note how the school describes student success and need (e.g., by percentages, by } \\
\text { grade levels). Indicate the baseline data (either existing or collected) source(s) and what these mean. }\end{array}$ \\
\hline $\begin{array}{l}\text { LEARNING CONTENT: Describe the subject area and content objectives being targeted. Indicate } \\
\text { what students are expected to know and be able to do. }\end{array}$ \\
\hline $\begin{array}{l}\text { STUDENT POPULATION: Provide a detailed description of the students targeted in the SLO (e.g., } \\
\text { grade levels/performance levels/demographics/etc.) }\end{array}$ \\
\hline $\begin{array}{l}\text { GROWTH TARGET: Describe the area of need you have targeted and how you intend to impact it } \\
\text { in a particular time frame for the given student population. }\end{array}$ \\
\hline $\begin{array}{l}\text { EVIDENCE OF GROWTH: Indicate the assessments being used to determine impact. Collect and } \\
\text { organize assessment data. Present findings in a graphic form to demonstrate impact. Include } \\
\text { attachments of data. }\end{array}$ \\
\hline
\end{tabular}




\section{MInstitute Macrothink $_{\text {Int }}$}

Global Journal of Educational Studies

ISSN 2377-3936

2019, Vol. 5, No. 2

STRATEGIES: Detail the specific instructional strategies used to impact the identified student population. Describe the intervention procedure.

INSTRUCTIONAL INTERVAL: Outline the timeframe for the SLO implementation and what portion represents your involvement.

TEACHER PROFESSIONAL LEARNING AND SUPPORT: Consult expert sources at the school. Examine the interventions in place. Consult the department chairperson, the subject specific school enrichment specialist, the reading specialist, and the special education instructor for guidance on the best practices that are in place at the PDS. Study the professional literature (at least one professional journal article or book as well as the internet) about best practice(s) for assisting students. Summarize the relevant findings of the consultations and literature. Identify areas of professional learning and support that might be needed.

\begin{tabular}{l}
\multicolumn{1}{c|}{ Analysis } \\
\hline $\begin{array}{l}\text { Interpret the patterns you found in the baseline and in the collected data. Relate your interpretations } \\
\text { to the expert opinions and professional literature sources that you researched. Note any surprises or } \\
\text { confirmations. }\end{array}$ \\
\hline $\begin{array}{l}\text { State the results of the project. What were the successes and challenges? Describe these in terms of } \\
\text { data collected. }\end{array}$ \\
\hline \multicolumn{1}{|l|}{ Reflection \& Presentation } \\
\hline What went well and what were some of the problems/obstacles of this SLO process? \\
\hline Describe any changes in process that were made along the way. \\
\hline What would you do similarly and differently the next time around given the same circumstances? \\
\hline To whom and in what forum will you present findings? \\
\hline
\end{tabular}

Note. Gray highlighted sections indicate portions completed in the first semester of the student teaching year.

\section{Copyright Disclaimer}

Copyright for this article is retained by the author(s), with first publication rights granted to the journal.

This is an open-access article distributed under the terms and conditions of the Creative Commons Attribution license (http://creativecommons.org/licenses/by/3.0/). 